\title{
Development of production technology for preparation of beetroot powder using different drying methods
}

\author{
Durga Shankar Bunkar*, Anima Anand*, Kamalesh Kumar Meena*, S. K. Goyal** and V. K. Paswan* \\ Department of Dairy and Food Microbiology, CDFT, MPUAT, Udaipur-313001, Rajasthan, India \\ *Department of Dairy Science and Food Technology, Institute of Agricultural Sciences, BHU, Varanasi-221005, Uttar Pradesh, India \\ **Department of Farm Engineering, Institute of Agricultural Sciences, BHU, Varanasi-221005, Uttar Pradesh, India
}

\section{Article Info}

Article history

Received 12 September 2020

Revised 28 October 2020

Accepted 30 October 2020

Published online 30 December 2020

\section{Keywords}

Antioxidant

Beetroot

Betalains

Lyophilized drying

Storage studies

\begin{abstract}
In recent years, the root vegetable, Beta vulgaris L. has attracted significant attention as a healthpromoting functional food product because it is a rich source of betalains and has high antioxidant capacity. So, there is an increased interest in preserving its nutrients through drying. In this study, the fresh beetroots (Vulgaris) were cleaned, peeled, crushed, and sliced longitudinal in four parts. The sliced beetroot dried separately by sun drying $\left(35-45^{\circ} \mathrm{C}\right)$, tray drying (at different temperature i.e., 40,50 and $60^{\circ} \mathrm{C}$ ) and lyophilizer drying $\left(-40^{\circ} \mathrm{C}\right)$, followed by grinding to powder using mixer grinder and subsequently packed in LDPE bags separately and stored at room temperature $\left(25-30^{\circ} \mathrm{C}\right)$ for shelf life studies. The beetroot powder quality was assessed by using proximate composition, physicochemical and sensory analysis. There was significant amount of variation in chemical composition and organoleptic quality of different beetroot powders but the powder prepared through lyophilizer had higher total phenolic content $(0.58 \mathrm{mg}$ gallic acid eq/g), betalain content $(4.89 \mathrm{mg} / \mathrm{g})$ and antioxidant activity (DPPH free radical scavenging activity) $(95.31 \%)$, compared to all other drying methods used. The statistical analysis in response of sensory properties of taste panel revealed that the beetroot powder obtained by lyophilizer was most acceptable with respect to color retention, flavour, texture and overall quality of product than the other drying methods.
\end{abstract}

\section{Introduction}

Beetroot (Beta vulgaris L.) is botanically classified as an herbaceous biennial from Chenopodiaceae family and has several varieties with bulb colors, ranging from yellow to red. It is the taproot portion of the beet plant, also known by many names as red or golden beet, the table beet, garden beet, or simply we called as the beet. Beetroot is grown all over the world in temperate areas, with main production centered in North America, Europe, Asia and North Africa (Kowalski and Szadzinska, 2014). It is a traditional and popular vegetable all over the world (Sawicki et al., 2016). Red beetroot has many uses in human nutrition. It can be used in various forms as red food colorants, e.g., to improve the colour of tomato paste, sauces, desserts, jams and jellies, ice cream, sweets and cereals (Gokhale and Lele, 2011; Kaur and Singh, 2014), as well as in dried forms like chips, tea, powder in bakery, in food supplements, etc. Beetroot is composed of $87.57 \%$, water, $9.56 \%$ carbohydrates ( $29.3 \%$ fiber and $70.7 \%$ sugar), $1.61 \%$ protein, and $0.17 \%$ lipids in addition to being a source of potassium, choline, vitamin $\mathrm{C}$, and niacin (USDA, 2013). Red beetroot is rich in valuable active compounds such as carotenoids, betalains, polyphenols, flavonoids,

Corresponding author: Dr. Kamalesh Kumar Meena Assistant Professor and Incharge, Department of Dairy and Food Microbiology, CDFT, MPUAT, Udaipur-313001, Rajasthan, India E-mail: kamleshrj14@gmail.com

Tel.: +91-9680184316 and saponins (Figiel, 2010; Kaur and Singh, 2014; Nistor et al., 2017). The betalains (nitrogen-containing pigments), red pigment found in beetroot is commonly added to foods as a source of red purple color. Its quantity in red beetroot is influenced by several factors as: species, variety, cultivation area, ripening period and storage (Nistor et al., 2017). It is a major source of betalains and protects humans against stress related disorder by inhibiting the lipid oxidation and peroxidation (Kaur and Kapoor, 2002). Due to its strong antioxidant potential, betalains possess an intense antibacterial and antiviral activity (Kowalski and Szadzinska, 2014), also protect human body from age related disease as well as from cancer, cardiovascular diseases by removing free radicals (Tsai et al., 2009; Pandey et al., 2018). The claimed therapeutic use of beetroot includes its antitumor, carminative, and hemostatic and renal protective properties and is a potential herb used in cardiovascular conditions (Vali et al., 2007; Singh and Hathan, 2014).

In recent years, increased attention has been focused on utilization of healthy foods. So, it has attracted significant attention as a healthpromoting functional food product (Clifford et al., 2015) due to the multitude of health benefits, associated with consumption of beetroot which would increase accessibility to betalains. Betalains degrade easily when extracted and stored in the form of a solution. Its stability is also affected during processing (Gokhale and Lele, 2011) and these are highly sensitive to temperature, $\mathrm{pH}$, light intensity, oxygen, sugar and enzymes activity (Kowalski and Szadzinska, 2014; Pandey et al., 2018). However temperature is 
the most determining factor for betalain decomposition within the optimal pH. Drying is an alternative to the consumption of fresh fruits and vegetables, and allows their use during the off-season. The dried beetroot powder have an extended shelf life, decreased risk of microbial hazards, function as a strongly colored pigment, and can be used as value-added ingredients in a variety of food products. The colour and flavor of dried red beetroot are considered to be the most important quality attributes, affecting the degree of the product acceptability by the consumer (Sorour and El-Mesery, 2014). However, dehydration of beetroot while maintaining high content of betalains is a challenge. Spray drying or convective drying is recommended to avoid colorant degradation (Desai and Park, 2005). Spray drying essentially involves the addition of maltodextrin or other binders (Koul et al., 2002; Gokhale and Lele, 2011), and as a result, spray dried powder is less bright. Further, thermal degradation adds to the loss in betalain and red color. Hygroscopic nature of spray dried power is yet another limitation. The drying methods applied may affect to various extents the colour, shape, structure, nutritional and nutraceutical components. Therefore, it is very important to find an optimal drying temperature and rational heat dosage (Figiel, 2010; Kowalski and Szadzinska, 2014). In this study, other alternative drying options have been explored for the dehydration of beets into powders, using a sun drying, tray drying at different temperatures, and freeze drying. This article reports the comparative effects of different drying techniques and storage studies on betalains pigment retention, the antioxidant activity, physicochemical properties and sensory characteristics of beetroot powder for up to 2 months was studied. There is no scientific work available on this earlier.

\section{Materials and Methods}

The study was carried out in the "Department of Dairy Science and Food Technology", Institute of Agricultural Sciences, Banaras Hindu University, Varanasi, Banaras, Uttar Pradesh, India. The chemicals used were Merck A. R. grade. The beetroot variety (Vulgaris) was collected from the local market of Lanka area, Varanasi. The cleaned beetroots were peeled and then cut into slice. Then sliced beetroot crushed in food processor, Make: Philips, Model: HR 7629 then dried at different temperatures by using sun drying, tray drying and lyophilization methods. Dried beetroot powder prepared in mixer grinder Make: Philips, Model: HL 7720. Low density polyethylene (LDPE) pouches were used for packaging of dried powder. All analysis was performed in triplicate.

\subsection{Drying protocol}

The sliced beetroot crushed in food processor then dried at different temperatures by using the following methods shown in Figure 1. In sun drying method, crushed beetroots $(1 \mathrm{~kg})$ were spread on a stainless steel tray $(40 \times 70 \mathrm{~cm})$ and kept in sun for drying. For tray drying, crushed beetroots $(1 \mathrm{~kg})$ were placed as a single layer on a stainless steel tray and dried in tray drier (Khera Instrument Pvt. Ltd.) at 40,50 and $60^{\circ} \mathrm{C}$ till crushed beetroots crisp. The lypohilization of fresh beetroot to prepare beetroot powder is done using the lyophilizer (NSW-275, Narang Scientific Works Pvt. Ltd., New Delhi) at temperature: $-40^{\circ} \mathrm{C}$, vacuum pressure: $0.5 \mathrm{~m}$.bar as performed by Singh et al. (2015) for preparing chili powder.

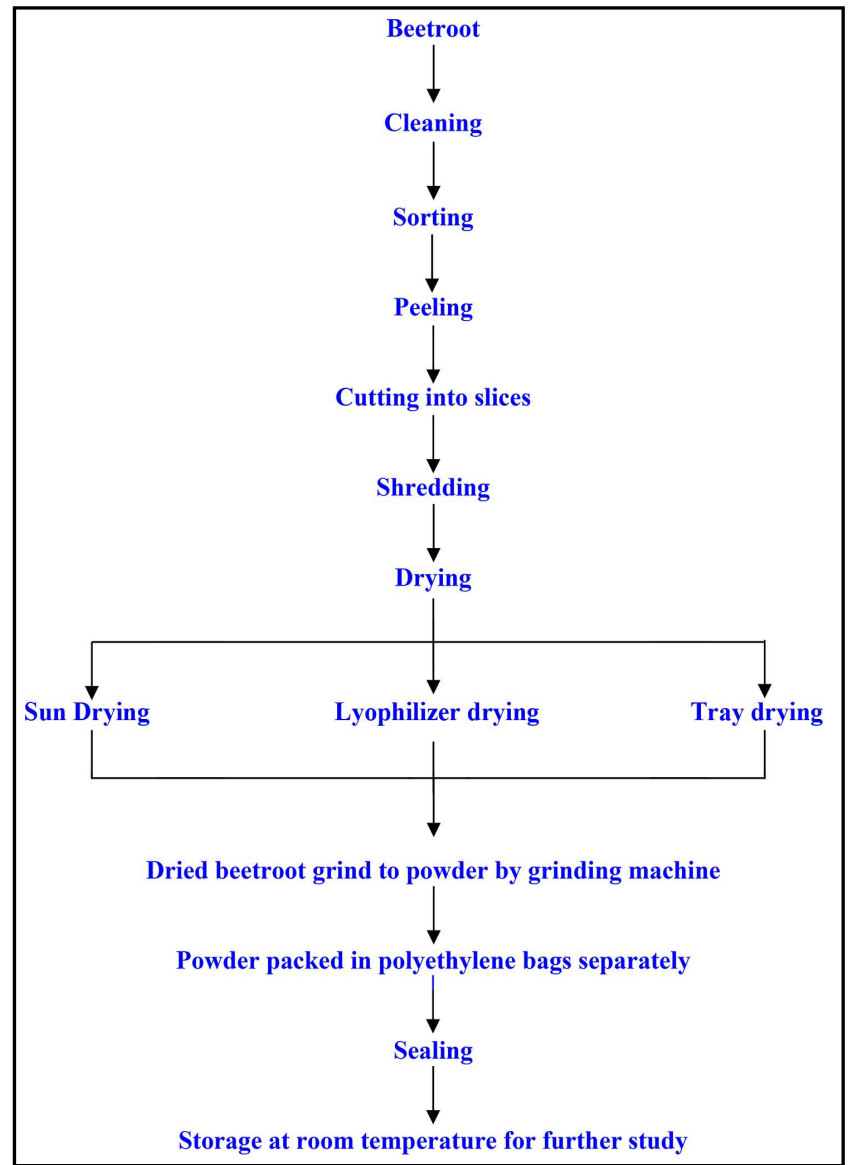

Figure 1: Flow diagram for the preparation of beetroot powder.

\subsection{Proximate analysis}

In proximate analysis, $\mathrm{pH}$, moisture content, crude fat, crude protein, ash content, antioxidant activity, reducing sugar, betalains, heavy metals like iron and calcium, and total phenolic content (TPC) were analyzed. The different physicochemical properties of beetroots powder were analyzed. The fat content of product was estimated by using Soxhlet apparatus. $5 \mathrm{~g}$ of sample was weighed in to the thimble and inserted in Soxhlet extractor. A clean and dry $150 \mathrm{ml}$ round bottom flask was accurately weighed and approximately $90 \mathrm{ml}$ of petroleum ether was poured into the flask. The content of the flask was heated at $70^{\circ} \mathrm{C}$ for one and half hour and then the temperature was increased to $140^{\circ} \mathrm{C}$ for evaporation for next one hour. The flask was removed from flask in an oven at $102^{\circ} \mathrm{C}$ until a constant weigh is reached (1-2 h). Then, the flask was cooled in a desiccator and the flask and contents was weighed (AOAC, 2000). Assessment of free fatty acids (omega 3 and omega 6) are based on titration, where oils or fats need to be dissolved in hot neutralized ethanol or ethanol/diethyl ether using phenolphthalein as an end point indicator (Mahesar et al., 2014). To determine fibre content, method suggested by Ranganna (2001) was employed. 2 g of beetroot powder was taken and approximately $0.5 \mathrm{~g}$ of asbestos, to the digestion flask. Added $200 \mathrm{ml}$ of concentrated sulphuric acid solution immediately connected the digestion flask with condenser, 
and heated. After 30 min heated sodium hydroxide under reflux condenser, washed the residue in acid digestion back in to the flask with $200 \mathrm{ml}$ of boiling sodium hydroxide solution. After $30 \mathrm{~min}$ of boiling, dry the crucible and contents at $110^{\circ} \mathrm{C}$ to a constant weight. Cool in a desiccators and weight. Ignite the contents of the crucible in an electric muffle furnace or over a burner at dull red heat until carbonaceous matter is destroyed. Cool in a desiccators and weight. The loss in weight represents the crude fibre. The protein was analyzed using Kjeldhal method described by MacDonald et al. (1977). The ash and moisture content of powder was determined by using the methods of AOAC (2000). Sugars in the products were estimated by Lane and Eynon's method reported by (Ranganna, 2001). Analysis of iron content were done as per AOAC (2000) using Flame Atomic Absorption Spectrophotometer (FAAS), Model AA-7000, Shimadzu, Japan, which was analyzed spectrophotometrically as per AOAC (2005).

\subsection{Antioxidant analysis: DPPH radical scavenging assay}

The 2,2-diphenyl-1-picrylhydrazyl radical (DPPH) assay was carried out by using (Shimadzu, UV Vis-1800, Tokyo, Japan). In this assay, antioxidants present in the sample reduce the DPPH radicals. For preparing the extract, beetroot powder sample $(1 \mathrm{ml}$ per $10 \mathrm{ml}$ ) was centrifuged at $10,000 \mathrm{rpm}$ for $15 \mathrm{~min}$. The supernatant collected was used in the assay. The DPPH radical solution was prepared by dissolving $10 \mathrm{mg}$ of DPPH in $25 \mathrm{ml}$ of $80 \%$ ethanol. $1 \mathrm{ml}$ from the dilution was incubated with $3 \mathrm{ml}$ of DPPH solution for $30 \mathrm{~min}$ in darkness. After $30 \mathrm{~min}$ incubation period at room temperature, the absorbance was read against a blank at $517 \mathrm{~nm}$.

$$
(\% \text { inhibition })=100 \times\left(\mathrm{A}_{\text {blank }}-\mathrm{A}_{\text {sample }} / \mathrm{A}_{\text {blank }}\right)
$$

where, $A_{\text {blank }}$ is the absorbance of the control reaction (containing all reagents except the test compound) and $\mathrm{A}_{\text {sample }}$ is the absorbance of the test compound. Percentage Inhibition of the activity of DPPH solution by the beetroot powder was, thus calculated and antioxidant activity was estimated. The DPPH-free radical scavenging capacity of vegetables was assessed by means of the method devised by Chen and Ho, (1995) and modified by Xu and Chang (2007) and Nistor et al. (2017).

\subsection{Analysis of betalain and total phenolic content}

For the betalains' spectrophotometric determination, the experiment was conducted using the method used by Ravichandran et al. (2013) and Nistor et al. (2017). For extraction of betalains, $0.1 \mathrm{~g}$ of beetroot powder was added to $10 \mathrm{ml}$ water. The samples were mixed with a vortexer (Standard Mini Vortexer, VWR Scientific Products, Radnor, PA) until homogeneous and then centrifuged with a centrifuge (Centrific Model 228, Fisher Scientific, Hampton, NH) for $10 \mathrm{~min}$ at $3300 \mathrm{rpm}$. The supernatant was collected and the insoluble portion was re-extracted and the supernatant was combined and brought to a final volume of $50 \mathrm{ml}$ with water in a volumetric flask at room temperature (Kujala et al., 2000). Betalain extracts were diluted with $0.05 \mathrm{M}$ phosphate buffer, $\mathrm{pH} 6.5$ so that the samples exhibited absorption between 0.4 and $0.5 \mathrm{AU}$ at $\lambda \max =538 \mathrm{~nm}$.
A spectrophotometer (Spectronic Genesys 2, Thermo Electron Corporation, Madison, WI) was used to measure the absorption of the samples, were recorded at 476, 538, and $600 \mathrm{~nm}$. Corrected light absorptions of betanin and vulgaxanthin-I were calculated according to Elbe et al. (2005). The total phenolic content was determined by the Folin-Cioclteau method (Singh et al., 2002; Nistor et al., 2017). Samples (2 gm) were homogenized in n-hexane at room temperature and centrifuged in cold at 10,000 rpm for $15 \mathrm{~min}$ and the supernatant was extracted. The residue obtained was re-extracted twice and the supernatants were collected, poured into petri-dishes and evaporated at dryness at room temperature. Then, the residue was dissolved in $5 \mathrm{ml}$ of distilled water. $100 \mu \mathrm{ml}$ of this extract was diluted to $3 \mathrm{ml}$ of water and $0.02 \mathrm{ml}$ of Folin-Cioclteau reagent was added. After $3 \mathrm{~min}, 2 \mathrm{ml}$ of $20 \%$ of sodium carbonate was added and the contents were mixed thoroughly. A color developed and the absorbance measured at $725 \mathrm{~nm}$ in UV-Spectrophotometer, using gallic acid as a standard. The results were expressed as mg gallic acid/100 $\mathrm{g}$ fresh material.

\subsection{Physicochemical analysis}

The $\mathrm{pH}$ was analyzed using digital $\mathrm{pH}$ meter (LAB India Instruments Pvt. Ltd., Mumbai) after calibration, using a standard buffer solution at $30^{\circ} \mathrm{C}$ each day before use. The sinkability of beetroot powder was measured by spectrophotometric method as described by Sammhammer (1966). In this, $3.5 \mathrm{ml}$ of distilled water at $20^{\circ} \mathrm{C}$ was taken in the Spectrophotometer cuvette and $10 \mathrm{mg}$ sample of powder was dusted on the surface of water and the percentage transmittance was measured at $760 \mathrm{~nm}$ in a Spectrophotometer. The readings were recorded after 2, 4 and 6 min intervals. The mean of three replicate values was taken as the percentage transmittance.

Bulk density was determined by Sahin-Nadeem et al. (2013) method. A $100 \mathrm{ml}$ graduated cylinder of tarred weight was taken. The mouth of cylinder and the powder was allowed to flow freely to $100 \mathrm{ml}$ mark. The net weight was obtained and results expressed as $\mathrm{g} / \mathrm{ml}$ (loose density). The tapped bulk density was determined by tapping the cylinder till the volume attained a constant level. The volume occupied was noted and result expressed as $\mathrm{g} / \mathrm{ml}$.

The color of beetroot powder was analyzed by using Spectrophotometer (Hunter color lab), manufactured by $\mathrm{M} / \mathrm{s}$ Hunter associate laboratory Inc-USA. In order to obtain the $\mathrm{L}^{*}$ (Lightness), $\mathrm{a}^{*}$ (green/red), and $\mathrm{b}^{*}$ (blue/yellow) value, the lens of the color reader was placed on the powder. Triplicate samples were analyzed and the results were recorded.

\subsection{Microbial analysis}

The total plate count (TPC) for the product is determined using the plate count agar (Hi Media, Mumbai, India) after incubating the plates for $48 \mathrm{~h}$ at $37^{\circ} \mathrm{C}$ in appropriate dilutions (APHA, 1984). The yeast and molds were estimated with the help of potato dextrose agar (PDA, HiMedia, Mumbai, India) after incubation at $25^{\circ} \mathrm{C}$ for 4-5 days. 


\subsection{Sensory analysis}

In the present study the beetroot powder samples were subjected to sensory evaluation using 9-point hedonic scale. The sensory evaluation was performed by a panel of 15 semi trained judges (aged 25-35 years) from the Department of Dairy Science and Food Technology, Institute of Agricultural Sciences, Banaras Hindu University, Varanasi, India. The judges gave score of preference (by 9 point hedonic rating scale) of color, flavour and overall acceptability and the score preference data is shown in Table 5. The samples were served in plastic odourless trays. Water was used for rinsing the trays before using it for other samples. Sensory evaluation was carried out at $25^{\circ} \mathrm{C}$ and $60 \%$ relative humidity (Ranganna, 2001).

\subsection{Statistical analysis}

For statistical analysis, all the experiments, conducted in triplicates and data were evaluated by One-way ANOVA (Analysis of variance) procedures of Statistical Analysis System (SAS, 1985).

\subsection{Storage studies}

The samples of beetroot powder dried under sun, tray and lyophilizer drying were separately packed and sealed in low density polyethylene (total gauge - $90 \mu \mathrm{m}$, weight per area $-82.2 \mathrm{~g} / \mathrm{m}^{2}$ and sealing condition: $150^{\circ} \mathrm{C} / 5 \mathrm{bar} / 1.0 \mathrm{sec}$ ) and stored at room temperature for further studies upto 60 days. Packaging material and storage temperature are known to influence the chemical and physical properties of dried products. The selection criteria of a suitable packaging material for beetroot powder was essentially based on shelf life.

\section{Results}

The fresh beetroot (B. vulgaris) analyzed for moisture, protein, fat, ash, and betalain content and results are shown in Table 1. The results were different to proximate chemical composition of fresh beetroots per $100 \mathrm{gm}$ as calories $43 \pm 1.50 \mathrm{kcal}, 88 \pm 1.50 \%$ moisture content, $9.6 \pm 2.20 \mathrm{~g}$ carbohydrate, $1.96 \pm 0.84 \mathrm{~g}$ protein, $0.2 \pm 0.02 \mathrm{~g}$ fat, $2.8 \pm 0.40 \mathrm{~g}$, fibre, and $1.18 \pm 0.62 \mathrm{~g}$ iron content. A small variation is observed due to climatic condition, soil property and growing condition, harvesting period, maturity stage, agro-ecological condition and temperature used for drying. The yield of beetroot powder was 10 to $12 \mathrm{~g}$ per $100 \mathrm{gm}$ of fresh beetroot. Lack of differences in dry matter content in roots of red beet produced by various technologies was reported by Sikora et al. (2010) and Kazimierczak et al. (2011).
3.1 Proximate analysis, antioxidant and phenolic contents

The chemical composition (chemical analysis) and proximate analysis of beetroot (B. vulgaris) powder for moisture, fat, ash, protein, reducing sugar, antioxidant, total phenolic content (TPC), and betalain content were analyzed. The results are presented in Table 2. The moisture content of the samples was between $5.52 \pm 0.61 \%$ per 100 gm powder and plotted in Figure 2. An increase in temperature leads to decrease in moisture content. The results recorded for ash content were ranging from $4.23 \pm 0.48$ to $5.26 \pm 0.51 \%$ in beetroot powder. The results of protein content observed were ranging from $1.12 \pm 0.23$ to $1.96 \pm 0.43 \%$ on dry basis per $100 \mathrm{gm}$ sample of beetroot powder. The fat percentage found in the range of $0.2 \pm 0.05$ to $0.28 \pm 0.07 \%$. The betalain content decreases with increase in temperature in different drying methods. An increase in temperature leads to decrease in betalain content from $4.89 \pm 0.73 \mathrm{mg} / \mathrm{g}$ to $3.10 \pm 0.83 \mathrm{mg} / \mathrm{g}$. The results obtained by the different drying methods used for drying beetroot was ranged from $15.5 \pm 1.19$ to $11.49 \pm 1.08 \mathrm{mg} \mathrm{GAE} / \mathrm{g}$ levels of TPC. The beetroot contains very good amount of iron content. The iron content observed under sun drying was $1.18 \pm 0.20 \mathrm{~g}$ and under lyophilization drying, it was found $1.56 \pm 0.22 \mathrm{~g}$. The amount for iron under tray drying at $40^{\circ} \mathrm{C}$ was $1.25 \pm 0.30 \mathrm{~g}$, at $50^{\circ} \mathrm{C}$ was $1.22 \pm 0.22 \mathrm{~g}$, and at $60^{\circ} \mathrm{C}$ was $1.16 \pm 0.32 \mathrm{~g}$. Drying probably increased antioxidant activity due to increase in concentration of bioactive molecules in the food matrix without large loss. The antioxidant value observed by applying different drying methods on beetroot powder were significantly higher and the value ranges from $95 \pm 0.68 \%$ in beetroot powder. But, there was a decrease in antioxidant activity at $50^{\circ} \mathrm{C}$, which then goes on increasing with increase in temperature of treatment which is also shown in Figure 3.

Table 1: Proximate analysis of fresh beetroot (per $100 \mathrm{gm}$ )

\begin{tabular}{|l|c|}
\hline Nutrients & Compositions \\
\hline Calories & $43 \pm 1.50 \mathrm{kcal}$ \\
Water & $88 \pm 1.50 \%$ \\
Carbohydrate & $9.6 \pm 2.20 \mathrm{~g}$ \\
Protein & $1.96 \pm 0.84 \mathrm{~g}$ \\
Fiber & $2.8 \pm 0.40 \mathrm{~g}$ \\
Sugar & $6.8 \pm 1.20 \mathrm{~g}$ \\
Fat & $0.2 \pm 0.02 \mathrm{~g}$ \\
Saturated & $0.03 \pm 0.002 \mathrm{~g}$ \\
Monounsaturated & $0.03 \pm 0.003 \mathrm{~g}$ \\
Omega 3 & $0.01 \pm 0.002 \mathrm{~g}$ \\
Omega 6 & $0.06 \pm 0.002 \mathrm{~g}$ \\
Iron & $1.18 \pm 0.62 \mathrm{~g}$ \\
\hline
\end{tabular}

Values are Mean \pm standard deviation $(n=3)$.

Table 2: Comparative analysis of proximate composition of beetroot powder

\begin{tabular}{|l|r|l|l|l|l|l|l|l|l|}
\hline Sample & Moisture (\%) & Fat (\%) & Ash (\%) & Iron (g) & Protein (\%) & $\begin{array}{l}\text { Reducing } \\
\text { sugar (\%) }\end{array}$ & $\begin{array}{l}\text { TPC } \\
\text { (mg GAE/g) }\end{array}$ & $\begin{array}{l}\text { Antioxidant } \\
\text { activity (\%) }\end{array}$ & $\begin{array}{l}\text { Betalain } \\
\text { content (mg/g) }\end{array}$ \\
\hline SDBP & $10.0 \pm 0.53$ & $0.20 \pm 0.06$ & $5.26 \pm 0.51$ & $1.18 \pm 0.20$ & $1.54 \pm 0.62$ & $21.8 \pm 0.95$ & $11.49 \pm 1.08$ & $61.5 \pm 2.53$ & $3.10 \pm 0.83$ \\
TDBP $40^{\circ} \mathrm{C}$ & $5.4 \pm 0.63$ & $0.22 \pm 0.05$ & $4.28 \pm 0.63$ & $1.25 \pm 0.30$ & $1.56 \pm 0.53$ & $22.6 \pm 1.51$ & $14.41 \pm 1.27$ & $89.0 \pm 1.98$ & $3.62 \pm 0.97$ \\
TDBP $50^{\circ} \mathrm{C}$ & $4.5 \pm 0.83$ & $0.21 \pm 0.03$ & $4.52 \pm 0.54$ & $1.22 \pm 0.22$ & $1.49 \pm 0.57$ & $23.0 \pm 1.73$ & $13.43 \pm 1.14$ & $85.6 \pm 2.01$ & $3.62 \pm 0.78$ \\
TDBP $60^{\circ} \mathrm{C}$ & $4.0 \pm 0.72$ & $0.20 \pm 0.05$ & $5.23 \pm 0.37$ & $1.16 \pm 0.32$ & $1.12 \pm 0.23$ & $21.9 \pm 0.99$ & $12.51 \pm 1.30$ & $82.0 \pm 1.76$ & $3.48 \pm 0.65$ \\
LDBP & $3.6 \pm 0.35$ & $0.28 \pm 0.07$ & $4.23 \pm 0.48$ & $1.56 \pm 0.22$ & $1.96 \pm 0.43$ & $21.3 \pm 0.73$ & $15.58 \pm 1.19$ & $95.31 \pm 1.93$ & $4.89 \pm 0.73$ \\
\hline
\end{tabular}

Values are Mean \pm standard deviation $(\mathrm{n}=3)$

SDBP- Sun Dried Beetroot Powder, TDBP- Tray Dried Beetroot Powder (40, 50 and $\left.60^{\circ} \mathrm{C}\right)$, LDBP- Lyophilized Dried Beetroot Powder 


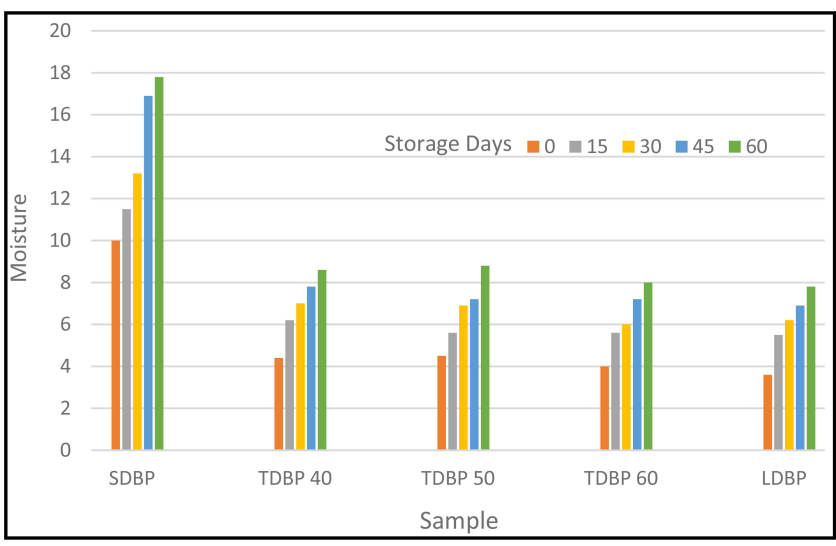

Figure 2: Moisture retention of beetroot powder.

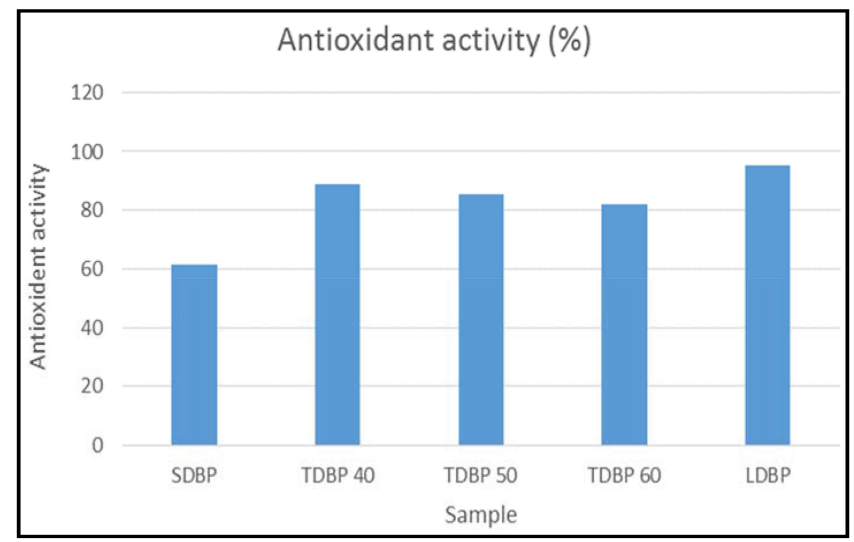

Figure 3: Percentage of antioxidant activities for different drying methods.

most reliable criterion to evaluate the behavior of powder in aqueous solution. This parameter is attained after the powder undergoes dissolution steps of sinkability, dispersability and wettability (Chen and Patel, 2008) and results for sinkability are shown in Table 4. The data shows that, there was significant difference $(p<0.01)$ between all the drying methods studied. Color is the important organoleptic property of beetroot powder which changes according to change in temperature. As the temperature increases, the betalain content decreases so the colour also decreases with rise in temperature.

Table 3: Physicochemical analysis of beetroot powder

\begin{tabular}{|c|c|c|c|c|c|c|}
\hline \multirow{3}{*}{\multicolumn{2}{|c|}{ Component }} & \multicolumn{5}{|c|}{ Drying methods } \\
\hline & & \multirow[t]{2}{*}{ Sun drying } & \multicolumn{3}{|c|}{ Tray drying } & \multirow[t]{2}{*}{ Lyophilizer drying } \\
\hline & & & $40^{\circ} \mathrm{C}$ & $50^{\circ} \mathrm{C}$ & $60^{\circ} \mathrm{C}$ & \\
\hline \multicolumn{2}{|c|}{ Bulk density $\left(\mathrm{g} / \mathrm{cm}^{3}\right)$} & $0.1699 \pm 0.04$ & $0.1689 \pm 0.05$ & $0.1855 \pm 0.04$ & $0.1836 \pm 0.03$ & $0.1543 \pm 0.03$ \\
\hline \multicolumn{2}{|c|}{ Tapped density $\left(\mathrm{g} / \mathrm{cm}^{3}\right)$} & $0.1769 \pm 0.06$ & $0.1736 \pm 0.04$ & $0.1933 \pm 0.03$ & $0.1978 \pm 0.04$ & $0.1649 \pm 0.08$ \\
\hline \multirow[t]{3}{*}{ Colour } & $\mathrm{L}$ & $18.94 \pm 1.20$ & $22.37 \pm 1.32$ & $21.74 \pm 1.26$ & $19.94 \pm 2.01$ & $17.84 \pm 1.86$ \\
\hline & $\mathrm{a}$ & $12.6 \pm 1.20$ & $16.56 \pm 1.32$ & $15.24 \pm 1.23$ & $13.62 \pm 1.24$ & $10.20 \pm 1.16$ \\
\hline & $\mathrm{b}$ & $2.65 \pm 0.86$ & $2.94 \pm 0.56$ & $3.59 \pm 0.78$ & $3.75 \pm 0.64$ & $2.09 \pm 0.76$ \\
\hline \multicolumn{2}{|l|}{ pH } & $6.8 \pm 0.16$ & $6.0 \pm 0.15$ & $6.2 \pm 0.26$ & $6.5 \pm 0.43$ & $5.9 \pm 0.22$ \\
\hline
\end{tabular}

Values are Mean \pm standard deviation $(n=3)$.

Table 4: Sinkability of beetroot powder

\begin{tabular}{|c|c|c|c|c|c|}
\hline \multirow[t]{3}{*}{ Parameter } & \multicolumn{5}{|c|}{ Drying methods } \\
\hline & \multirow[t]{2}{*}{ Sun drying } & \multicolumn{3}{|c|}{ Tray drying } & \multirow[t]{2}{*}{ Lyophilizer drying } \\
\hline & & $40^{\circ} \mathrm{C}$ & $\mathbf{5 0}^{\circ} \mathrm{C}$ & $60^{\circ} \mathrm{C}$ & \\
\hline 2 minute & $28.90 \pm 2.32$ & $30.40 \pm 1.62$ & $33.29 \pm 1.64$ & $34.55 \pm 1.68$ & $30.30 \pm 2.01$ \\
\hline 4 minute & $24.55 \pm 1.56$ & $29.14 \pm 1.53$ & $32.22 \pm 1.67$ & $33.63 \pm 1.58$ & $32.04 \pm 1.69$ \\
\hline 6 minute & $21.04 \pm 1.86$ & $26.33 \pm 1.98$ & $28.12 \pm 1.62$ & $28.43 \pm 1.76$ & $19.19 \pm 1.32$ \\
\hline
\end{tabular}

Values are Mean \pm standard deviation $(n=3)$.

\subsection{Sensory evaluation of beetroot powder}

The results evaluated by panelist for color of sun dried beetroot powder were $8.22 \pm 2.72$, tray dried beetroot powder at $40^{\circ} \mathrm{C}$ were $8.67 \pm 0.50$; at $50^{\circ} \mathrm{C}$ were $8.55 \pm 0.53$; at $60^{\circ} \mathrm{C}$ were $6.67 \pm 1.00$ and for lyophilizer $8.77 \pm 0.44$. Results for flavour of sun dried beetroot powder were $8.11 \pm 0.78$, tray dried beetroot powder at 40 were $8.55 \pm 0.53$; at 50 were $8.67 \pm 0.50$; at $60^{\circ} \mathrm{C}$ were $6.22 \pm 0.67$; and for lyophilizer dried powder, the results were $8.99 \pm 0.44$. The results for overall acceptability of beetroot powder obtained by applying different drying methods such as sun dried beetroot 
powder were $8.22 \pm 0.78$, tray dried beetroot powder at $40^{\circ} \mathrm{C}$ were $8.67 \pm 0.11$; at $50^{\circ} \mathrm{C}$ were $8.22 \pm 0.48$; at $60^{\circ} \mathrm{C}$ were $6.99 \pm 0.44$; and for lyophilizer dried powder, the results were $8.999 \pm 0.5$. The analysis of variance showed that there was a significant difference with respect to color, flavour and overall acceptability at $1 \%$ level of significance $(p<0.01)$.

\subsection{Microbial analysis of beetroot powder}

The microbiological analysis of beetroot powder for total plate count and yeast and mould count were analyzed and the results are presented in Table 6. The microbial count largely depends upon the quality of raw material used in the product preparation and the method of processing. The type of package and temperature of storage also showed significant influence on the growth and survival of microorganisms in beetroot powder. The total plate count was found minimum for tray drying method at $60^{\circ} \mathrm{C}\left(8.2 \times 10^{3} \mathrm{cfu} / \mathrm{gm}\right)$ but yeast and mold count was found minimum in lyophilized beetroot powder $\left(6.6 \times 10^{1} \mathrm{cfu} / \mathrm{gm}\right)$.

Table 5: Hedonic score (1-9) of beetroot powder for color, flavour and overall acceptability

\begin{tabular}{|l|l|l|l|}
\hline $\begin{array}{l}\text { Drying Methods } \\
\text { (Sa mple) }\end{array}$ & Color & Flavour & $\begin{array}{l}\text { Overall } \\
\text { acceptability }\end{array}$ \\
\hline Sun drying & $8.22 \pm 2.72$ & $8.11 \pm 0.78$ & $8.22 \pm 0.78$ \\
Tray drying at $40^{\circ} \mathrm{C}$ & $8.67 \pm 0.50$ & $8.55 \pm 0.53$ & $8.67 \pm 0.11$ \\
Tray drying at $50^{\circ} \mathrm{C}$ & $8.55 \pm 0.53$ & $8.67 \pm 0.50$ & $8.22 \pm 0.48$ \\
Tray drying at $60^{\circ} \mathrm{C}$ & $6.67 \pm 1.00$ & $6.22 \pm 0.67$ & $6.99 \pm 0.44$ \\
Lyophilizer drying & $8.77 \pm 0.44$ & $8.99 \pm 0.44$ & $8.99 \pm 0.50$ \\
\hline
\end{tabular}

Values are Mean \pm standard deviation $(n=3)$.

\subsection{Storage studies of beetroot powder}

The effects of packaging material and storage time on the composition of beetroot powder during 60 days storage were studied and the results are presented in Table 7. The initial moisture content of sun drying $10.0 \pm 0.78$, lyophilizer $3.6 \pm 0.35$ and tray drying at 40,50 and $60^{\circ} \mathrm{C}$ were $5.4 \pm 0.63,4.5 \pm 0.83$ and $4.0 \pm$ 0.72 , respectively. The beetroot powder absorbed the moisture content during storage and leads to increase in moisture content in stored product. Sun dried powder moisture content increases from $10.0 \pm 0.78$ to $17.8 \pm 0.18$, in lyophilizer from $3.6 \pm 0.35$ to $7.8 \pm$ 0.45 and in tray dried powder at 40,50 and $60^{\circ} \mathrm{C}$ the moisture content increases from $5.4 \pm 0.63$ to $8.6 \pm 0.61 ; 4.5 \pm 0.83$ to $8.0 \pm$ 0.61 and 4.0 to $8.0 \pm 0.28$, respectively after 60 days storage. The effect of packaging material on physical properties of beetroot powder was studied in terms of bulk density (Table 7). The bulk density was increases with increase in storage period. There was no significant difference in flavor on the samples of beetroot powder within 60 days of storage. The flavor of beetroot powder packed in polyethylene bags was retained lower and flavor become slightly changed after 60 days of storage. The texture was fine and very smooth for sun, tray $\left(40,50\right.$ and $\left.60^{\circ} \mathrm{C}\right)$ and lyophilizer dried powder on the day of preparation. But, the texture of beetroot powder packed in polyethylene bags changed slightly from fine and smooth grain to coarse after 60 days of storage. The slight reduction in texture quality that observed in beetroot powder might be due to the absorption of moisture from the environment.

Table 6: Microbial analysis of beetroot powder

\begin{tabular}{|c|c|c|c|c|c|}
\hline \multirow[t]{3}{*}{ Microbial test } & \multicolumn{5}{|c|}{ Drying methods } \\
\hline & \multirow{2}{*}{$\begin{array}{l}\text { Sun drying } \\
(\mathrm{cfu} / \mathrm{gm})\end{array}$} & \multicolumn{3}{|c|}{ Tray drying (cfu/gm) } & \multirow{2}{*}{$\begin{array}{l}\text { Lyophilizer drying } \\
\text { (cfu/gm) }\end{array}$} \\
\hline & & $40^{\circ} \mathrm{C}$ & $50^{\circ} \mathrm{C}$ & $60^{\circ} \mathrm{C}$ & \\
\hline Total plate count & $11 \times 10^{3}$ & $9.2 \times 10^{3}$ & $8.9 \times 10^{3}$ & $8.2 \times 10^{3}$ & $10.5 \times 10^{3}$ \\
\hline Yeast and mold count & $8.0 \times 10^{1}$ & $7.5 \times 10^{1}$ & $6.3 \times 10^{1}$ & $6.7 \times 10^{1}$ & $6.4 \times 10^{1}$ \\
\hline
\end{tabular}

Table 7: Effect of packaging material and storage time on bulk density and moisture content at room temperature of beetroot powder

\begin{tabular}{|c|c|c|c|c|c|c|c|c|c|c|}
\hline \multicolumn{11}{|c|}{ Characteristic of beetroot powder } \\
\hline \multirow{3}{*}{$\begin{array}{l}\text { Storage } \\
\text { (Days) }\end{array}$} & \multirow{2}{*}{\multicolumn{2}{|c|}{ Sun drying }} & \multicolumn{6}{|c|}{ Tray drying } & \multirow{2}{*}{\multicolumn{2}{|c|}{ Lyophilizer drying }} \\
\hline & & & \multicolumn{2}{|c|}{$40^{\circ} \mathrm{C}$} & \multicolumn{2}{|c|}{$50^{\circ} \mathrm{C}$} & \multicolumn{2}{|c|}{$60^{\circ} \mathrm{C}$} & & \\
\hline & \begin{tabular}{|l|} 
Moisture \\
content $(\%)$
\end{tabular} & $\begin{array}{l}\text { Bulkdensity } \\
\left(\mathrm{g} / \mathrm{cm}^{3}\right)\end{array}$ & $\begin{array}{l}\text { Moisture } \\
\text { content }(\%)\end{array}$ & $\begin{array}{l}\text { Bulkdensity } \\
\left(\mathrm{g} / \mathrm{cm}^{3}\right)\end{array}$ & $\begin{array}{l}\text { Moisture } \\
\text { content }(\%)\end{array}$ & $\begin{array}{l}\text { Bulkdensity } \\
\left(\mathrm{g} / \mathrm{cm}^{3}\right)\end{array}$ & $\begin{array}{l}\text { Moisture } \\
\text { content (\%) }\end{array}$ & $\begin{array}{l}\text { Bulkdensity } \\
\left(\mathrm{g} / \mathrm{cm}^{3}\right)\end{array}$ & $\begin{array}{l}\text { Moisture } \\
\text { content }(\%)\end{array} \mid$ & $\begin{array}{l}\text { Bulkdensity } \\
\left(\mathrm{g} / \mathrm{cm}^{3}\right)\end{array}$ \\
\hline $\mathbf{0}$ & $10.0 \pm 0.53$ & $0.1699 \pm 0.078$ & $54.4 \pm 0.63$ & $0.1710 \pm 0.032$ & $4.5 \pm 0.83$ & $0.1855 \pm 0.029$ & $4.0 \pm 0.72$ & $0.1836 \pm 0.036$ & $3.6 \pm 0.35$ & $0.1543 \pm 0.026$ \\
\hline 15 & $11.5 \pm 0.68$ & $0.1704 \pm 0.029$ & $6.2 \pm 0.32$ & $0.1714 \pm 0.036$ & $5.6 \pm 0.29$ & $0.1862 \pm 0.028$ & $5.6 \pm 0.52$ & $0.1838 \pm 0.071$ & $5.5 \pm 0.23$ & $0.1547 \pm 0.037$ \\
\hline 30 & $13.2 \pm 0.63$ & $0.1714 \pm 0.063$ & $7.0 \pm 0.45$ & $0.1719 \pm 0.038$ & $6.9 \pm 0.72$ & $0.1868 \pm 0.036$ & $6.0 \pm 0.47$ & $0.1844 \pm 0.067$ & $6.2 \pm 0.32$ & $0.1593 \pm 0.063$ \\
\hline 45 & $16.9 \pm 0.27$ & $0.1722 \pm 0.042$ & $7.8 \pm 0.51$ & $0.1728 \pm 0.062$ & $7.2 \pm 0.53$ & $0.1877 \pm 0.042$ & $7.2 \pm 0.38$ & $0.1853 \pm 0.063$ & $6.9 \pm 0.34$ & $0.1602 \pm 0.051$ \\
\hline 60 & $17.8 \pm 0.18$ & $0.1730 \pm 0.041$ & $8.6 \pm 0.61$ & $0.1738 \pm 0.027$ & $8.8 \pm 0.61$ & $0.1885 \pm 0.039$ & $8.0 \pm 0.28$ & $0.1865 \pm 0.064$ & $7.8 \pm 0.45$ & $0.1611 \pm 0.067$ \\
\hline
\end{tabular}

Values are Mean \pm standard deviation $(\mathrm{n}=3)$.

\section{Discussion}

The variation in proximate analysis between beetroot samples were observed due to difference in preparation and method employed. At lower drying temperatures, constant drying rate was lower and moisture kept on diffusing to the surface, resulting in lower critical moisture content and increases in temperature, increases the drying 
rate considerably, compared to the lower moisture content which was almost negligible. Singh et al. (2015) used sun, tray, vacuum and lyophilized drying to prepare chilli powder in which moisture varies from 7.9 to $9.9 \%$ in final product. The variation in ash content between beetroot samples were also are in line with study done for chilli powder by Singh et al. (2015). There is no change in protein content during storage on dry matter basis. The results were more or less similar to Sharma and Prasad, (2004) who observed that the percentage of fat ranging from 0.19 to $0.2 \%$ per 100 gm sample of beetroot powder. The betacyanin in beets consists of 75 to $95 \%$ betanin and betaxanthin comprises roughly $95 \%$ vulgaxanthin (Piatelli, 1981; Mukundan et al., 1998). Betalain, the most prominent betalain in beets, can undergo many forms of degradation during thermal processing, including isomerization, decarboxylation or cleavage by heat and acids (Herbach et al., 2006). Betalain degrade easily when extracted and stored in the form of a solution. The lack of difference between betacyanin and vulgaxanthin content between samples dried at different temperatures suggests that the amount of heat transferred to the samples during dehydration was not enough to degrade the pigment. The total phenolic count (TPC) increases with increase in temperature due to loss of selective compounds at higher temperature. Increase in TPC may be due to increase in extractability of phenolic compounds other than betalains with increase in extraction temperature. The reduction in antioxidant activity may be due to the degradation of betacyanin at this temperature. But, with an increase in temperature, some thermo-chemical reactions resulted in the formation of antioxidants other than phenolic compounds. There was increase in antioxidant activity with increase in drying temperature was due to betaxanthin content and also with the compounds formed because of the degradation of betacyanin. In some cases, increase in antioxidant activity may be due to the formation of compounds other than phenolic compounds as a result of degradation of betalain at higher temperatures (Pitalua et al., 2010).

For drying methods (viz., spray, drum and freeze drying), the bulk density of mango powders increased and their porosity decreased with decreasing particle size (Caparino et al., 2012). These results may be attributed to the decrease in the inter-particle voids of smaller sized particles with larger contact surface areas per unit volume. Xiaoyan (2008) reported similar observation for bulk density of ginger powder at different particle sizes. Barbosa-Canovas et al. (2005) also explained that powder characteristics such as particle size may result in significant changes in bulk density and porosity. Caparino et al. (2012) reported that there was no significant difference in the solubility between spray and drum-dried mango powder, while both were significantly higher, compared to refractive window and freeze-dried product $(p \leq 0.05)$. The high solubility of spray-dried mango powder can be attributed to the addition of maltodextrin. The color of the dried product (mango flakes/sheet) or powders of different particle sizes were affected by the drying methods (Caparino et al., 2012). The color degradation that observed in the beetroot powders can be attributed to the exposure of the beetroot product in sun light, fluctuation in sun temperature during day, higher heat treatment and time for mechanical drying and composition of beetroot. The color of beetroot varied from dark to light red which is dependent on betalain pigment present in beetroot.
With the observation that increase in drying temperature decreases betalain content (red pigment), it was thought that at increased temperature, betacyanin was converted to betaxanthin. The color pigments at higher temperature goes up to 65 and $72^{\circ} \mathrm{C}$, respectively which could result in thermochemical changes (Gokhale and Lele et al., 2010), but at 40,50 and $60^{\circ} \mathrm{C}$, there was very less effect on it. With the increase in extraction temperature, there was a decrease initially; colour loss was increased with increase in temperature. The microbial counts are in concurrence with study done for preparation of green chilling powder (Singh et al., 2015). The microbial counts in beetroot powder were depends upon the initial microbial load, hygienic conditions of processing and processing methods applied.

The results for the effect of packaging material and storage time on the composition of beetroot powder are consistent with those reported by Driscoll et al. (1985) and chemical deterioration in milk powder was faster at $21^{\circ} \mathrm{C}$ storage temperature than at $10^{\circ} \mathrm{C}$. It is difficult to ascertain whether the slight increase in moisture content in the sample was due to increase in moisture or the chemical changes, occurring during storage. Bulk density of beetroot powder increased with the storage period, irrespective of packaging material used. Kerekreti (1980) reported that there was increase in bulk density with increased moisture content in dried milk powder and ice cream mix. The increased bulk density was attributed to increased cohesiveness caused by absorption of moisture during storage. Amongst all the drying methods, the result obtained by lyophilizer drying is best as compared to all other drying methods used, viz., sun drying, and tray drying at various temperature (at 40,50 and $60^{\circ} \mathrm{C}$ ) for the preparation of beetroot powder. Hence, the above result indicated that lyophilized drying is more suitable for beetroot powder production than other drying methods.

\section{Conclusion}

The purpose of development of beetroot powder from fresh beetroot is to extend their shelf life and for further new product development. Freeze drying show lower TPC value due to selective loss of compounds during the drying process as phenolics are hydrosoluble compounds that may have been lost with water. There was less significant amount of variation in chemical composition and organoleptic quality of sun dried, tray dried $\left(40,50\right.$ and $\left.60^{\circ} \mathrm{C}\right)$ and lyophilizer dried beetroot powders. Beetroot powder prepared from lyophilizer dryer had higher total phenolic content, betalain content and antioxidant activities compared to all other drying methods, used in the study. The storage studies showed that bulk density and moisture of beetroot powder increased during storage at room temperature. The study demonstrated that the beetroot powder obtained by lyophilizer drying method, gave the best results, considering retention of color, flavour and overall quality of product than the other drying methods.

\section{Conflict of interest}

The authors declare that there are no conflicts of interest in the course of conducting the research. All the authors had final decision regarding the manuscript and decision to submit the findings for publication. 


\section{References}

AOAC (2000). Official methods of analysis, 17th Ed. Methods 925.10 965.17, 974.24, 992.16. The Association of Official Analytical Chemists, Gaithersburg, USA.

AOAC (2005). Official methods of analysis, 18th Ed. Association of Official Analytical Chemists, Gaithersburg, USA.

APHA (1984). Compendium of methods for the microbiological examination of foods, 2nd ed. American Public Health Association, Washington, DC.

Barbosa-Canovas, G.V.; Ortega-Rivas, E.; Juliano, P. and Yan, H. (2005). Food powders: Physical properties, processing, and functionality. Kluwer Academic/Plenum Publishers, New York.

Caparino, O.A.; Tang J.; Nindo, C.I.; Sablani, S.S.; Powers, J.R. and Fellman J.K. (2012). Effect of drying methods on the physical properties and microstructures of mango (Philippine 'Carabao' var.) powder. Journal of Food Engineering, 111:135-148.

Chen, C.W.; and Ho, C.T. (1995). Antioxidant properties of polyphenols extracted from green and black teas. Journal of Food Lipids, 2(1):35-46

Chen, X.D. and Patel, K.C. (2008). Manufacturing better quality food powders from spray drying and subsequent treatments. Drying Technology, 26:1313-1318.

Clifford, T.; Howatson, G.; Daniel, J.; West, D.J.; and Stevenson, E.J. (2015). The potential benefits of red beetroot supplementation in health and disease. Nutrients, 7:2801-2822.

Desai K.G.H. and Park H.J. (2005). Recent development in microencapsulation of food ingredients. Drying Technology, 23:1361-1394

Driscoll, D.J.; Martir, W.; Wang, J. X. and Lunsford, J.H. (1985). Formation of gas-phase methyl radicals over magnesium oxide. J. Am. Chem. Soc., 107(1):58-63.

Elbe, J.H.V. (2005). Betalains. R.E. Wrolstad (Ed.), Handbook of food analytical chemistry. pp:123-129, John Wiley and Sons, New York.

Figiel, A. (2010). Drying kinetics and quality of beetroots dehydrated by combination of convective and vacuum-microwave methods Journal of Food Engineering, 98(4):461-470.

Gokhale, S.V. and Lele, S.S. (2011). Dehydration of red beet root (Beta vulgaris) by hot air drying: Process optimization and mathematical modeling. Food Science and Biotechnology, 20(4):955-964.

Gokhale, S.V. and Lele, S.S. (2010). Optimization of convective dehydration of Beta vulgaris for colour retention. Food Bioprocessing Technology, 5(3):868-878

Herbach, K.M.; Stintzing, F.C. and Carle, R. (2006). Betalain stability and degradation: Structural and chromatic aspects. Journal of the Science of Food and Agriculture, 71:R41-R50

Kaur, C. and Kapoor, H.C. (2002). Antioxidant activity and total phenolic content of some Asian vegetables. International Journal of Food Science and Technology, 37:153-161.

Kaur, K. and Singh, A.K. (2014). Drying kinetics and quality characteristics of beetroot slices under hot air followed by microwave finish drying. African Journal of Agricultural Research, 9(12):1036-1044.

Kazimierczak, R.; Hellmamm, E.; Treščinska, V. and Rembiałkowska, E. (2011) Estimation of the nutritive value of two red beet (Beta vulgaris) varieties from organic and conventional cultivation. Journal of Research and Applications in Agricultural Engineering, 56(3):206-210.
Kerekreti, D. (1980). Regulation of moisture, bulk density, particle size and wettability of dried milk. Prumysl Potravin, 31:327-334.

Koul, V.K.; Jain, M.P.; Koul, S.; Sharma, V.K.; Tikoo, C.L. and Jain, S.M. (2002). Spray drying of beet root juice using different carriers. Indian J. Chem. Technol., 9(5):442-445.

Kowalski, S. J. and Szadzinska, J. (2014). Kinetics and quality aspects of beetroots dried in non-stationary conditions. Drying Technology, 32: $1310-1318$

Kujala, T.S.; Loponen, J.M.; Klika, K.D. and Pihlaja K. (2000). Phenolics and betacyanins in red beetroot (Beta vulgaris) root: Distribution and effect of cold storage on the content of total phenolics and three individual compounds. Journal of Agriculture and Food Chemistry, 48:5338-5342

Mahesar, S.A.; Sherazi, S.T.H.; Khaskheli, A.R.; Kandhro, A.A. and Sirajuddin (2014). Analytical approaches for the assessment of free fatty acids in oils and fats Issue. Analytical Methods, 14:4903-5398.

McDonald, J.M.; David, E.B.; Jarett, L. and Davis, J.E. (1977). A rapid microtechnique for the preparation of biological material for the simultaneous analysis of calcium, magnesium and protein. Analytical Chemistry, 82(2):485-492.

Mukundan, U.; Carvalho, E.B. and Curtis, W.R. (1998). Growth and pigment production by hairy root cultures of Beta vulgaris L. in a bubble column reactor. Biotechnology Letters, 20:469-474.

Nistor, O.V.; Ceclu, L.S; Andronoiu, D.G.; Rudi, L. and Botez, E. (2017). Influence of different drying methods on the physicochemical properties of red beetroot (Beta vulgaris L. var. Cylindra). Food Chemistry, 236:59-67.

Pandey, G.; Pandey, V.; Pandey, P.R. and Thomas, G. (2018). Effect of extraction solvent temperature on betalain content, phenolic content, antioxidant activity and stability of beetroot (Beta vulgaris L.) powder under different storage conditions. Plant Archives, 18(2): $1623-1627$.

Piatelli, M. (1981). Thebetalains: structure, biosynthesis and chemical taxonomy. In: Biochemistry of Plants, EE Conn, ed vol-7, pp:557-575 New York: Academic Press.

Pitalua, E.; Jimenez, M.; Vernon-Carter, E.J. and Beristain, C.I. (2010). Antioxidative activity of microcapsules with beetroot juice using gum arabic as wall material. Food Bioproducts Processing, 88:253-258.

Ranganna, S. (2001). Handbook of analysis and quality control for fruit and vegetable products, 2nd ed. Tata McGraw Hill Publications Co Ltd., Replika Press Pvt Ltd., Delhi.

Ravichandran, K.; Saw, N.M.M.T.; Mohdaly, A.A.A.; Gabr, M.M.A.; Kastell, A.; Riedel, H.; Cai, Z.; Knorr, D. and Smetanska, I. (2013). Impact of processing of red beet on betalain content and antioxidant activity. Food Research international, 50:670-675.

Sahin-Nadeem, H.; Dinçer, C.; Torun, M.; Topuz, A. and Özdemir, F. (2013). Influence of inlet air temperature and carrier material on the production of instant soluble sage (Salvia fruticosa Miller) by spray drying. LWT-Food Science and Technology, 52:31-38.

Sammhammer, E.A. (1966). Method for measuring instant properties of milk powder, Milchwissenschaft, 21:413-415.

Sawicki, T.; Baczek, N. and Wiczkowski, W. (2016). Betalain profile, content and antioxidant capacity of red beetroot dependent on the genotype and root part. Journal of Functional Foods, 27:249-261.

SAS (1985). SAS ${ }^{\circledR}$ Institute User's Guide; Statistics. Version 5 Edition. SAS Institute Inc., Cary, North Carolina 27513. 
Sharma, G.P. and Prasad, S. (2004). Drying of garlic (Allium sativum) cloves by microwave-hot air combination. Journal of Food Engineering, 50:99-105.

Sikora, M.; Klonowska, K.; Hallmann; E. and Rembiałkowska, E. (2010). Nutritive quality of red beet roots from organic and conventional production. In: Rembiałkowska E. (ed.), the impact of organic production methods on the vegetable product quality. pp:209-220, SGGW, Warszawa, Poland.

Singh, A; Chauhan, A.K.; Singh, R.P.; Yadav, P. and ALsebaeai, M.A.Q. (2015). Development of production technology to manufacture of green chili powder. Proceeding - Kuala Lumpur International Agriculture, Forestry and Plantation September 12-13, 2015. Hotel Putra, Kuala Lumpur, Malaysia.

Singh, B. and Hathan, B.S. (2014). Chemical composition, functiona properties and processing of beetroot: A review. International Journal of Scientific and Engineering Research, 5(1):679-684.

Singh, R.P.; Murthy, K.N.C. and Jayaprakash, G.K. (2002). Studies on the antioxidant activity of pomegranate peel and seed extracts using in vitro models. Journal Agriculture Food Chemistry, 50:81-86.
Sorour, H. and El-Mesery, H. (2014). Effect of microwave and infrared radiation on drying of onion slices. International Journal of Research in Applied, 2(5):119-130.

Tsai, P.J.; Sheu C.H.; Wu, P.H. and Sun, Y.F. (2009). Thermal and pH stability of betacyanin pigment of Djulis (Chenopodium formosanum) in Taiwan and their relation to antioxidant activity. Journal of Agricultural and Food Chemistry, 58:1020-1025.

United State Department of Agriculture (2013). National Nutrient Database for Standard Reference. http://ndb.nal.usda.gov/ndb/foods/list.

Vali, L.; Stefanovits-Banyai, E.; Szentmihalyi, K.; Febel, H.; Sardi, E.; Lugasi, A.; Kocsis, I. and Blazovics, A. (2007). Liver-protecting effects of table beet (Beta vulgaris var. Rubra) during ischemia-reperfusion. Nutrition, 23:172-178.

Xiaoyan, Z.Y. (2008). Effect of superfine grinding on properties of ginger powder. Journal of Food Engineering, 91(2):217-222.

Xu, B.J. and Chang, S.K.C. (2007). A comparative study on phenolic profiles and antioxidant activities of legumes as affected by extraction solvents. Journal of Food Science, 72(2):160-161.

Citation Durga Shankar Bunkar, Anima Anand, Kamalesh Kumar Meena, S. K. Goyal and V. K. Paswan (2020). Development of production technology for preparation of beetroot powder using different drying methods. Ann. Phytomed., 9(2):293301. http://dx.doi.org/10.21276/ap.2020.9.2.29 